\title{
@ccreative
}

\section{Un estado que se desvanece en la memoria}

\author{
CARLES Àngel SAURí \\ PAULA GARCÍA-MASEDO \\ (paula.g.masedo@gmail.com)
}

Este texto se nos ocurre como un diálogo, de manera parecida a cómo nos podríamos imaginar a Kassel hablando con Atenas. Toda comunicación es un fracaso, seguro que es, al menos, un fail en parte. Siempre queda la sensación de que algo queda por decir, y muchas más veces, por entender. Cierto es a veces, que sin palabras de por medio, o con unas palabras en concreto, muchas veces, con las palabras robadas a otro, aparece un enlace inesperado, inesperadamente eficaz, por invisible e inmaterial que sea. Probablemente esas palabras convocan imaginarios distintos en las cabezas de quienes nos hablamos, en cualquier caso, el vínculo está ahí.
"Kassel se desvanece en la memoria. Frente al Fridericianum un simulacro del Partenón intenta salvar de la ruina el espíritu cultural del templo griego a través de una reproducción de su arquitectura con libros, obra de Marta Minujín y Pierre Bal-Blanc. El Fridericianum, el museo público más antiguo de Europa, fue salvado de sus ruinas para la primera documenta en 1955. El núcleo central de la exposición establece un diálogo entre dos espacios clave para la cultura local de sus ciudades, dos edificios que fueron centro y ruina de los proyectos culturales de los que emergían. En el fondo, y visto desde la lejanía, este juego parece seguir promoviendo la narrativa cultural de una Europa que tiene

CÓMO CITAR ESTE TRABAJO / HOW TO CITE THIS PAPER

Saurí, C.A. y García-Masedo, P. (2018). Un estado quese desvanece en la memoria. Umática. Revista sobre Creación y Análisis de la Imagen, 1: 207-211.

http://www.revistas.uma.es/index.php/umatica/issue/current 


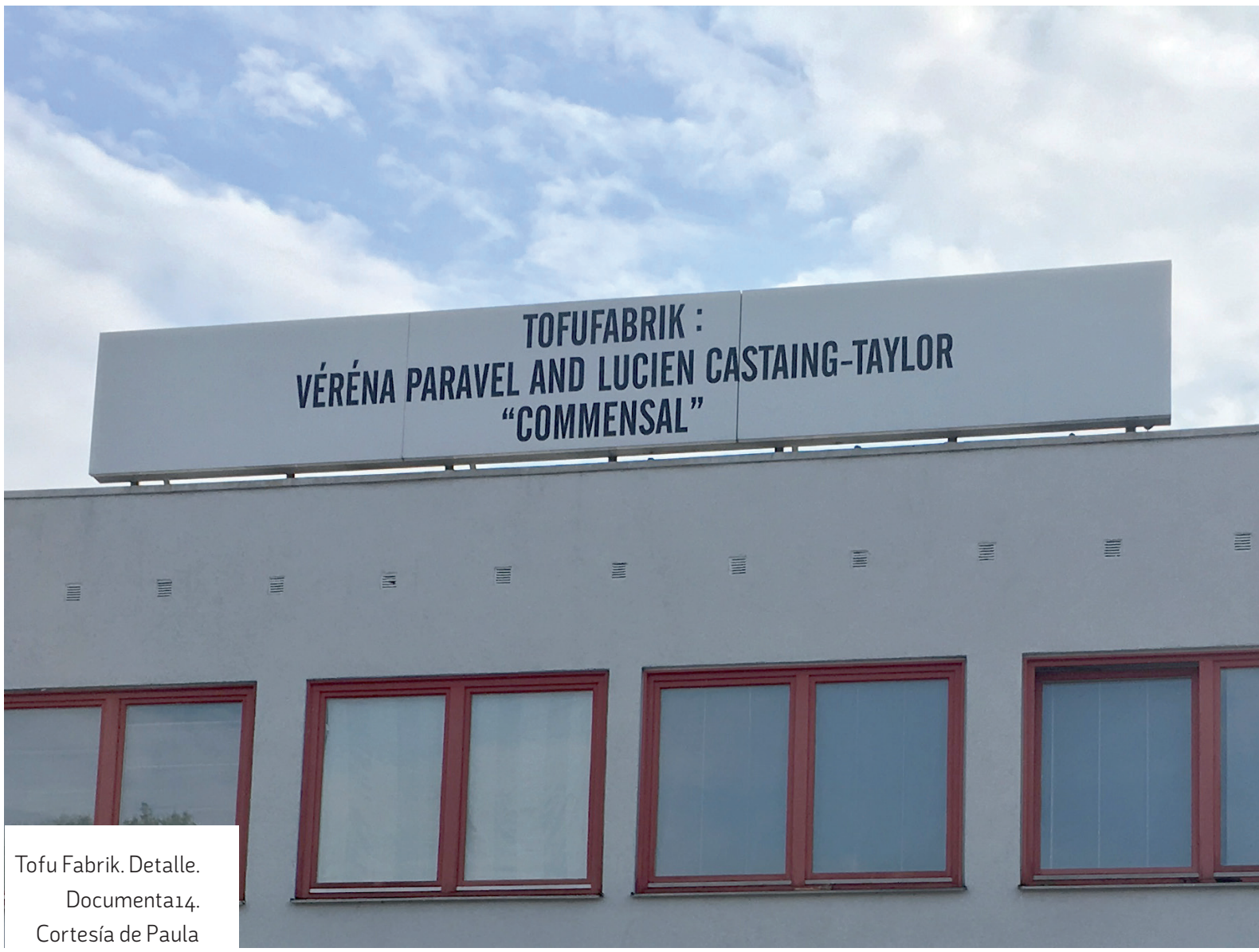

García Masedo y Carles Àngel. 2017. sus bases en la cultura griega, recuperadas por la ilustración y fetichizadas porla UE.

Tal vez, este sea el ejercicio que más haga dudar del discurso curatorial de la Ddocumental4, este querer huir desde dentro. Poner en crisis la idea de Europa desde un proyecto como documenta que nació como espacio de liberación artística (en parte también por la negación a ser una feria) para curar las heridas de un viejo continente deprimido, muchas veces entra en contradicción. Sin embargo, el fracaso me parece la narración más pertinente para la construcción de la idea de Europa y éste parece acompañar a muchos de los proyectos artísti- cos como el archivo de Stefanos Tsivopoulos en el mismo Fridericianum."

En la documenta, la memoria, el pasado, aparece como parte del presente. La separación entre ambos tiempos, pero su conexión inevitable - uno no es sin el otro- lleva implícita la idea de transformación, pero a veces, parece que señala que hemos llegado al mismo sitio de partida. De nuevo, esa idea de fracaso. El movimiento como tema subyace en el entendimiento que la documenta hace de lo contemporáneo: circulación de capital, deuda, desposesión, emigración, desplazamiento, diseminación. El movimiento, el link, se da entre sitios, y entre tiempos, está dentro de la estructura narrativa de la exposición. Así, algunas piezas, 


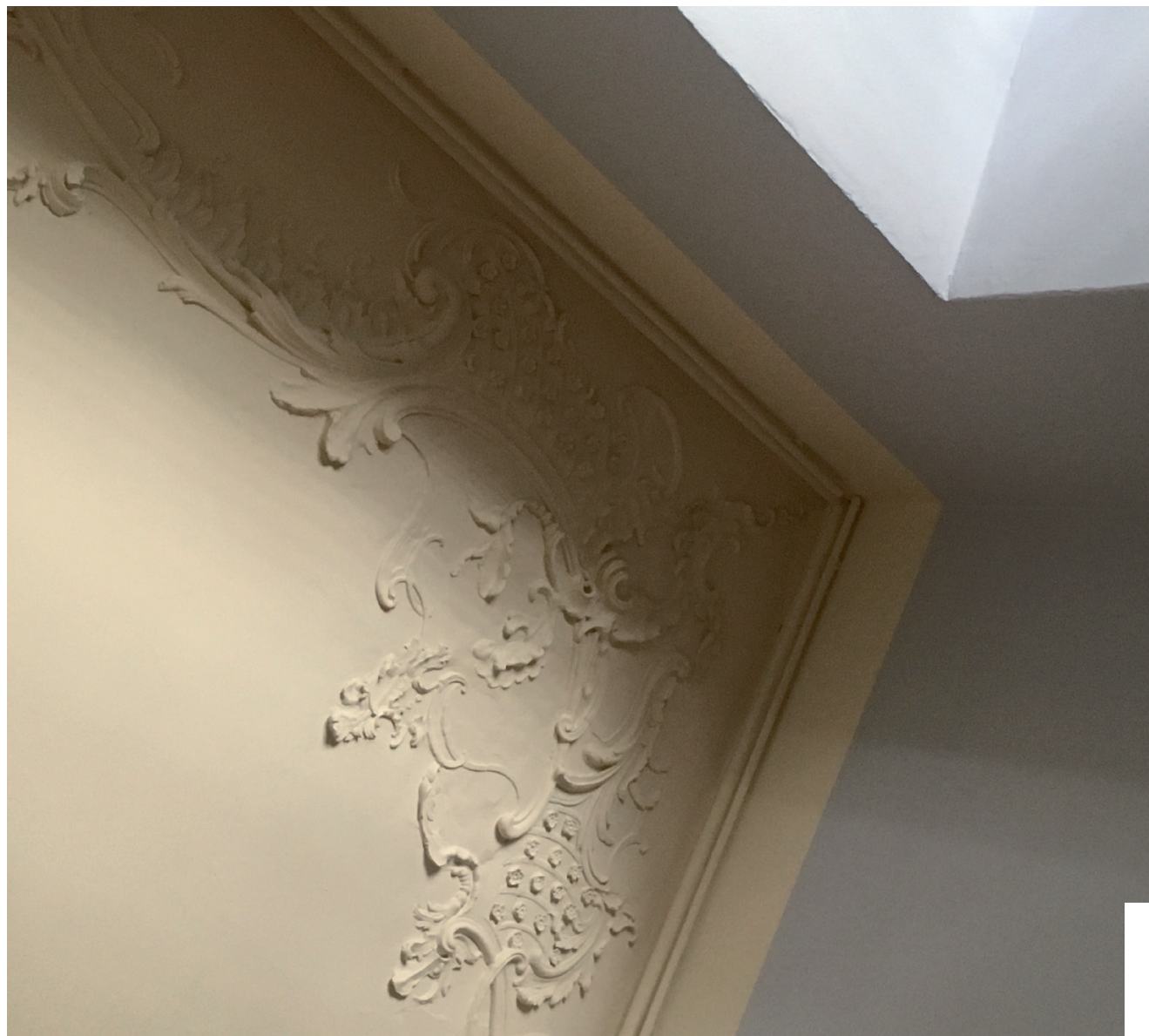

o historias, aparecen en varios lugares y en varios tiempos, pudiéndose componer narraciones más completas a través de la reunión de texturas, aunque esta composición a veces es tibia, casi azarosa. En South as a State of Mind, se puede leer el artículo de Jonas Mekas "I had nowhere to go", que tiene texto, y tiene fotos, y en un flyer del Bali Kino de Kassel están las fotos de Mekas; y las palabras de quien escribió ese texto están en el Cinestar de Kassel, y también en el Stella de Atenas. En realidad, de todo eso, es la voz de Mekas, en esa película de Douglas Gordon, la que verdaderamente coloca el pasado en el presente.

La recuperación del pasado tiene que ver con esa obsesión de los que ya han vivi- do bastante por contextualizar. El contexto se introduce como un relato a colocar junto a las piezas. En ocasiones percibimos cómo se crea el espacio metafóricamente acorde a las obras, introduciendo el texto a través de la arquitectura. Así, la construcción que aloja las piezas se corresponde con ellas mismas, como si la función o la historia (del edificio) siguiera el sentido (de la obra artística). Y por tanto, la arquitectura se construye, como infraestructura de sentido, una infraestructura perversa, caníbal, capitalista.

"Y donde el uno no es sin el otro, nos encontramos charlando con un caníbal en la Tofufabrik. El desplazamiento de la realidad pasada del edificio se convierte en una experiencia hostil.
Bellevue.

Documental4.

Cortesía de Paula García Masedo y Carles Àngel. 2017. 
En las entrañas de las salas donde se prepara el Tofu una pantalla hace de plataforma para empatizar con la exhumación de un carnívoro. La elección irónica del espacio por parte del equipo de documenta hace que el espectador entre en una contradicción espacial y conceptual del lugar que ocupa su cuerpo. A nivel individual, me vuelvo frágil mientras trato de leer las viñetas del cómic sádico que proyectaba Commensals. Me vuelvo una masa blanda y voluble frente al testimonio de Issei Sagawa. Durante la exhumación de los hechos narrados, en el relato turbulento de su pasado, el espectador se va distanciando cada vez más del presente y entra en el infatigable fracaso de repensar el pasado. El pasado es al fin una masa moldeable, sin forma y laxa, un trozo de tofu al que darle una forma para cada plato.

Pasado, presente... Atenas, Kassel... La contraposición de la historia con sus realidades presentes llega a su momento más estridente en la Neue Gallerie cuando Joseph Beuys se enfrenta a su retrato nazi en la instalación de Piotr Uklanski... Pienso si el arte es vida, o si la vida y el arte no son una serie de contradicciones que se apoyan en algo tan inestable como el pasado. El espectador debe entender que la interpretación objetiva e imparcial de una figura como Beuys, la
Neue Gallery o la vida es un ejercicio caníbal sobre su propio presente."

Parece que para la documenta el pasado está fijado y grabado en piedra, tanto que es inamovible desde el presente. Si a Beuys no se le debe soltar de su pasado, sobre las piedras de los palacios alemanes, la Neue Gallery, la Orangerie, pesa el pasado colonial. Los mejores lugares históricos (otra vez, la Neue Gallery, la Orangerie, Bellevue, los jardines), mantienen una belleza indudablemente imponente, armoniosa, sólida, eurocéntrica, serena.... ¿Pero cómo integrarlos en una exposición que intenta repensar la superioridad centroeuropea frente al sur? Parece que esta pregunta ha resonado, y su respuesta de nuevo alude al movimiento: piezas que trabajan ideas de nacionalismo y pertenencia, pérdida y dispersión; remitiendonos a un pasado que va desde el siglo XVII a la Segunda Guerra Mundial y el legado del fundador de la documenta, Arnold Bode. En Bellevue, de repente la exposición se vuelve amable, cómo no va a pasar, si entramos en una casa (aunque sea palaciega), dentro, donde artistas que juegan con la naturaleza como cultura, y como territorio. No puedo evitar ver algo romántico en todo esto, quizá es el influjo del edificio, pero claro, no vamos a negar que éste tiene también su aura.

En los jardines tampoco se escapa a esa ambivalencia, de repente, por ejemplo, 
una instalación de aire metafórico de Ciudad Abierta, la Escuela de Valparaíso. Es inevitable pensar, ¿qué hace aquí todo esto? Kassel se deshace por el borde en edificios industriales, se deshace por el centro en forma de arquitectura posmoderna y franquicias anodinas, rápidamente encontramos la ciudad genérica de la parte tardía del siglo XX, ese espacio basura del que hablaba Rem Koolhaas. El esfuerzo por contextualizar es grande, pero a la vez, la exposición habla de la periferia negando que ésta forma parte de Kassel, habla de la acumulación capitalista, acumulando obras, habla de que ya ni la posmodernidad nos sirve como resolución a la falta de utopías, dentro del contenedor posmoderno de la Documenta

I Koolhaas, Rem. La ciudad genérica. Gustavo Gili. Barcelona. 2006

\section{AUTORA:}

PAULA GARCÍA MASEDO es artista y comisaria, y vive actualmente entre Madrid y Valencia. Su trabajo se desarrolla desde los ámbitos de la arquitectura, el diseño y la cultura material, y a través del texto. Ha llevado a cabo los proyectos expositivos, como Las voces del GPS (CentroCentro, Madrid, 2018) además de otros. Ha desarrollado propuestas artísticas en Matadero Madrid, La Escocesa (Barcelona), y La Casa Encendida (Madrid). Estudió Arquitectura en la UPM (2011) y el Programa de Estudios Independientes del MACBA (2018)
Halle, sin ser capaz de transformar la forma de meterse dentro de este, sin poder impedir volverse un espectáculo en su interior.

"La documenta es éticamente exigente consigo misma. Continuamente apela a la razón, a nuestra mente. Cenamos en uno de los kebabs del centro de Kassel, iluminado con unos fluorescentes muy blancos, muy fríos. El espacio y el momento doblan estéticamente alguna de las piezas y sedes de la exposición, seguramente hay, además, un lugar muy parecido en Atenas. Necesitamos un proceso de entendimiento lento, pero en el estómago, como en la fábrica de tofu, ya sentimos algunas cosas. Desde ahí quizás se pueda sintonizar esa comunicación fracasada, seguir pensando, el pasado, el presente".

AUTOR:

CARLES ÀnGEL es miembro del Colectivo Nitrato de Chile. Es mediador en el Centro de Arte Bombas Gens, vive actualmente en Valencia. Desarrolla su trabajo a partir de la mediación, estrategias artísticas y la producción de texto. Estudió Bellas Artes en la UPV (2015) y el máster de Historia del Arte Contemporáneo y Cultura Visual de la UAM, UCM y el Museo Reina Sofía. Desarrolla el proyecto Horta Sonora, programa de composición de música contemporánea. 